\section{Full macular translocation following photodynamic therapy in neovascular age-related macular degeneration}

D Suesskind, M Voelker, KU Bartz-Schmidt and F Gelisken
Center for Ophthalmology, University of Tuebingen, Tuebingen, Germany

Correspondence:

F Gelisken,

Center for Ophthalmology, University of Tuebingen, Schleichstrasse 12, 72076 Tuebingen, Germany Tel: + 497071 2983721; Fax: 4970713730. E-mail: faik.gelisken@ med.uni-tuebingen.de

Received: 24 September 2006

Accepted in revised form: 28 December 2006 Published online: 30 March 2007

The authors have no financial interest

This work was presented at the annual meeting of the Association for Research in Vision and Ophthalmology, 30th April-4 May 2006, Fort Lauderdale
Abstract

Purpose To report the long-term functional and anatomical outcome of full macular translocation (FMT) in eyes with neovascular age-related macular degeneration (AMD) following photodynamic therapy (PDT). Methods Twelve eyes of $\mathbf{1 2}$ consecutive patients with neovascular AMD who were PDT-nonresponders and underwent FMT were analysed. Best-corrected visual acuity (BCVA) measurement, fundus photography, and fluorescein angiography at baseline and at follow-up examinations in 3 months intervals were performed. Primary end point was change of BCVA from baseline to last visit. Results Totally 12 eyes of 12 patients were analysed. Mean time interval between the last PDT and FMT was 3.7 months (range 1-10 months). Mean follow-up after FMT was 25.6 months. BCVA ranged at baseline from 20/1000 to 20/80 (mean 20/230). At the last visit, mean BCVA was by 20/185. BCVA improved in 50\% (6/12) of eyes by more than 1 line. Twenty five per cent (3/12) of eyes had final BCVA within \pm 1 line from baseline. In 25\% (3/12) of eyes the BCVA decreased by more than 1 line. One eye had recurrent CNV. In four eyes a cystoid macular oedema developed. No retinal detachment or disturbing diplopia was noted. Conclusions In the present study, FMT in PDT-nonresponders stabilised or improved visual acuity in the majority of the eyes in a mean follow-up period of nearly 2 years. FMT can be considered as a therapeutical option in eyes who are nonresponders to the PDT in neovascular AMD.
Eye (2008) 22, 834-837; doi:10.1038/sj.eye.6702738; published online 30 March 2007

Keywords: age-related macular degeneration; choroidal neovascularisation; photodynamic therapy; full macular translocation

Introduction

Age-related macular degeneration (AMD) is the major cause for legal blindness in the industrialised countries. ${ }^{1}$ Photodynamic therapy (PDT) using verteporfin (Visudyne; CIBA Vision Corp., Duluth, GA, USA) was proven to be beneficial for patients with predominantly classic subfoveal CNV in AMD. ${ }^{2}$ But a considerable amount of patients do not respond to the PDT.

Full macular translocation (FMT), which was first described by Machemer and Steinhorst, is a therapeutical option in selected cases of neovascular AMD. ${ }^{3-9}$ The purpose of this retrospective case study is to elucidate the long-term functional and morphological outcome of PDT-nonresponders who had undergone FMT in neovascular AMD.

\section{Materials and methods}

Twelve eyes of 12 patients with neovascular AMD treated between October 2001 and June 2005 at the Center for Ophthalmology in Tuebingen were included in this retrospective study. All patients had primary PDT and underwent FMT because of worsening of the vision following PDT. Ophthalmic examination included standardised best-corrected visual 
acuity (BCVA) measurement with ETDRS chart, fundus photography, and fluorescein angiography at baseline and at follow-up examinations in 3 months intervals.

Primary end point was change of BCVA from baseline to last visit.

Visual acuity Snellen equivalents were converted into $\log$ MAR units for statistical analysis.

PDT was performed according to the standard protocol described previously. ${ }^{2}$ The FMT was performed by one surgeon (KUB-S). A standard three port pars plana vitrectomy was carried out. After having removed the vitreous body and a small retinotomy at the inferior aquator, retinal detachment was created by injection of balanced salt solution by introducing a cannula through the retinotomy in the subretinal space. Following a $360^{\circ}$ retinotomy, the temporal part of the detached retina was rolled over the papilla and the $\mathrm{CNV}$ was removed. The retina was reattached by perfluorocarbon liquid and rotated superiorly in a region of healthy retinal pigment epithelium. Thereafter, a laser cerclage was performed and the retinotomy was surrounded with laser. Vitreous cavity was finally filled with silicone oil. Muscle surgery was either performed together with the FMT (two eyes) or in a second step together with the removal of the silicone oil (nine eyes). In one case no muscle surgery was carried out, because of lack of disturbing diplopia.

\section{Results}

Twelve eyes of 12 patients were analysed (five men and seven women). Their age ranged from 66 to 93 years (mean age 76 years). Before the first PDT, five eyes showed a subfoveal predominantly classic CNV. Four eyes had a subfoveal occult CNV (Figure 1). Two eyes had a retinal angiomatous proliferation (RAP), one in a juxtafoveal localisation, and the other one in a subfoveal localisation. One eye had a subfoveal minimally classic CNV.

Before the FMT, CNV lesion type had changed in some eyes: Of the five predominantly classic $\mathrm{CNV}$, three remained unchanged, one eye showed a large macular haemorrhage, and one eye developed a minimally classic $\mathrm{CNV}$. Three of the four eyes with occult $\mathrm{CNV}$ developed submacular haemorrhage that was larger than the CNV and one eye developed a minimally classic $\mathrm{CNV}$

(Figure 2). Two eyes with RAP lesion maintained this lesion type. The eye with the subfoveal minimally classic $\mathrm{CNV}$ developed macular haemorrhage that was larger than the CNV.

Follow-up ranged between 8 and 41 months (mean 25.6 months) (Table 1). Only two eyes had not completed the 1-year follow-up. In one patient, the examination was not possible because of the reduced general condition. The other patient was lost to follow-up.

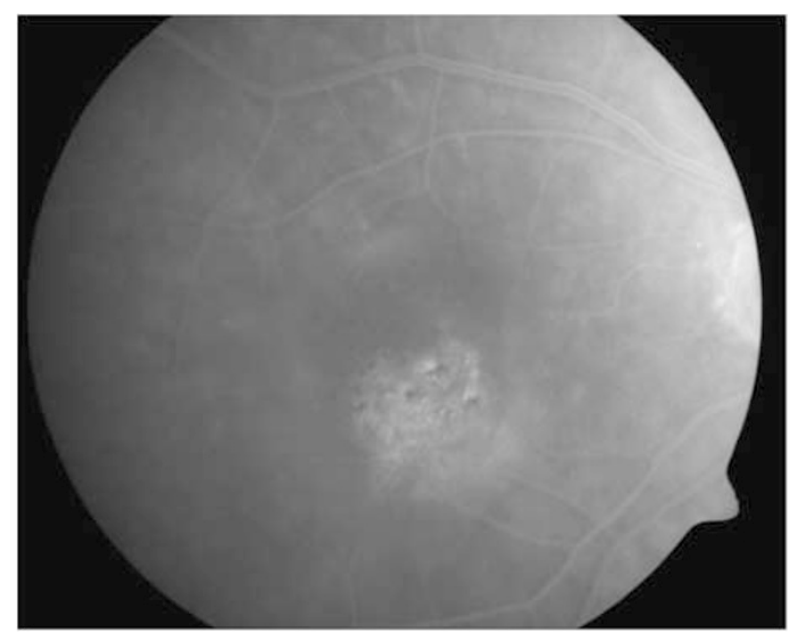

Figure 1 (Case 10) Late phase of the fluorescein angiogram showing an occult choroidal neovascularisation before the photodynamic therapy (visual acuity 20/63).

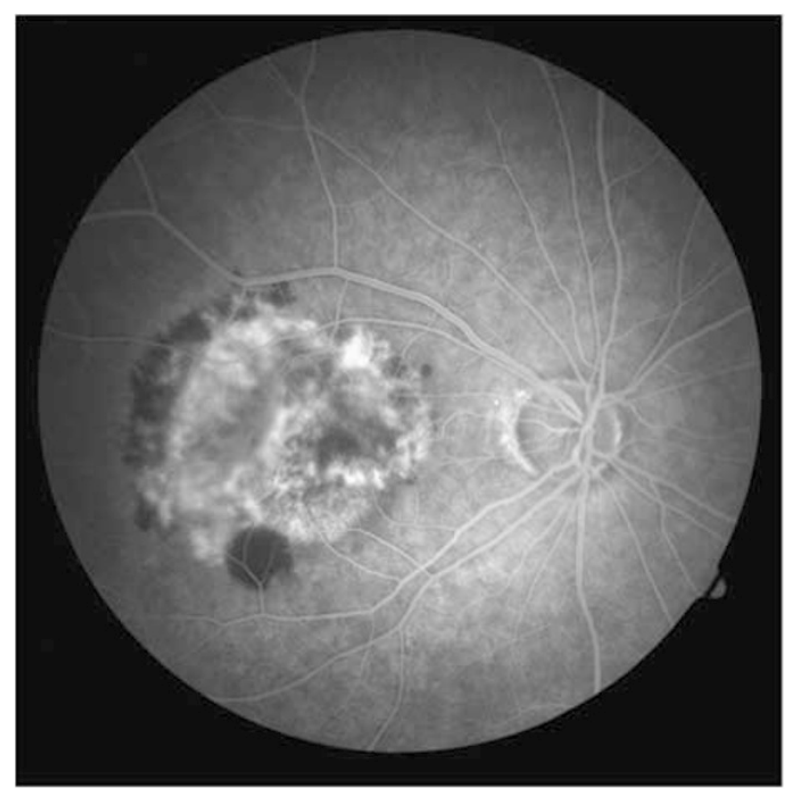

Figure 2 Mid phase of the fluorescein angiogram 8 months after the first photodynamic therapy demonstrates a growth of the choroidal neovascularisation (visual acuity 20/200).

Ten eyes had a follow-up of at least 12 months. Six eyes had a follow-up of at least 24 months and four eyes were followed up for 36 months or longer.

Mean BCVA before the first PDT was 20/63 (range 20/200-20/32). Eleven eyes experienced a vision decrease after the PDT. One eye had an unchanged vision but a subfoveal haemorrhage developed.

Before the FMT, mean BCVA was 20/230 (range 20/1000-20/80). At the last follow-up visit mean BCVA was 20/185 (range 20/1000-20/63). BCVA improved in seven of 12 eyes. In one eye vision improved by 8 lines 
Table 1 Demographic and clinical characteristics of the patients

\begin{tabular}{|c|c|c|c|c|c|c|c|c|c|c|}
\hline Case & Sex & $\begin{array}{l}\text { Age } \\
\text { (years) }\end{array}$ & $\begin{array}{l}\text { CNV-lesion } \\
\text { before PDT }\end{array}$ & $\begin{array}{l}\text { Number } \\
\text { of PDT }\end{array}$ & $\begin{array}{c}\text { Time interval } \\
\text { between PDT } \\
\text { and FMT } \\
\text { (months) }\end{array}$ & $\begin{array}{l}\text { CNV-lesion } \\
\text { before FMT }\end{array}$ & $\begin{array}{c}\text { BCVA before } \\
\text { the first } \\
\text { PDT }\end{array}$ & $\begin{array}{c}\text { BCVA before } \\
F M T\end{array}$ & $\begin{array}{l}\text { Last } \\
B C V A\end{array}$ & $\begin{array}{c}\text { Follow-up } \\
\text { after FMT } \\
\text { (months) }\end{array}$ \\
\hline 1 & $\mathrm{M}$ & 75 & o type 1 & 2 & 2 & sub hem & $\begin{array}{l}\text { Not } \\
\text { known }^{a}\end{array}$ & $20 / 200$ & $20 / 63$ & 36 \\
\hline 2 & $\mathrm{~F}$ & 79 & pred cl & 2 & 3 & sub hem & $20 / 200$ & $20 / 500$ & $\begin{array}{l}20 / \\
1000\end{array}$ & 8 \\
\hline 3 & $\mathrm{~F}$ & 71 & o type 1 & 1 & 1 & sub hem & $20 / 32$ & $20 / 200$ & $20 / 100$ & 40 \\
\hline 4 & M & 81 & RAP, stage III & 1 & 3 & RAP, stage III & $20 / 50$ & $20 / 250$ & $20 / 330$ & 41 \\
\hline 5 & $\mathrm{~F}$ & 70 & pred cl & 2 & 4 & pred cl & $\begin{array}{l}\text { Not } \\
\text { known }^{\text {a }}\end{array}$ & $20 / 400$ & $20 / 250$ & 17 \\
\hline 6 & $\mathrm{M}$ & 77 & RAP, stage III & 2 & 3 & RAP, stage III & $20 / 32$ & $20 / 80$ & $20 / 125$ & 34 \\
\hline 7 & M & 68 & pred cl & 3 & 10 & $\min \mathrm{cl}$ & $20 / 125$ & $20 / 1000$ & $20 / 160$ & 39 \\
\hline 8 & M & 93 & pred $\mathrm{cl}$ & 2 & 3 & pred $\mathrm{cl}$ & $20 / 63$ & $20 / 125$ & $20 / 100$ & 28 \\
\hline 9 & $\mathrm{~F}$ & 75 & o type 1 & 1 & 1 & sub hem & $20 / 100$ & $20 / 100$ & $20 / 660$ & 19 \\
\hline 10 & $\mathrm{~F}$ & 73 & o type 1 & 2 & 6 & $\min \mathrm{cl}$ & $20 / 63$ & $20 / 200$ & $20 / 125$ & 18 \\
\hline 11 & $\mathrm{~F}$ & 66 & pred cl & 1 & 3 & pred cl & $20 / 63$ & $20 / 400$ & $20 / 125$ & 17 \\
\hline 12 & $\mathrm{~F}$ & 85 & $\min \mathrm{cl}$ & 2 & 5 & sub hem & $20 / 40$ & $20 / 125$ & $20 / 160$ & 10 \\
\hline
\end{tabular}

Abbreviations: BCVA, best-corrected visual acuity; CNV, choroidal neovascularisation; F, female; FMT, full macular translocation; M, male; min cl, minimally classic $\mathrm{CNV}$; o, occult $\mathrm{CNV}$; PDT, photodynamic therapy; pred cl, predominantly classic CNV; RAP, retinal angiomatous proliferation; sub hem, subretinal haemorrhage.

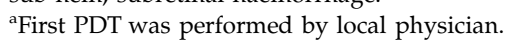

and in two eyes by 5 lines. In two eyes vision improvement of 2 lines was seen. In one eye vision improved by 3 lines (Figure 3) and in another eye by 1 line. Worsening of visual acuity was seen in five eyes. In two eyes a decrease in 1 line was noted. One eye had a worsening of 2 lines. One patient experienced a loss of 3 lines and one patient had a vision decrease of 8 lines.

Time interval between the last PDT and FMT varied between 1 and 10 months (mean: 3.7 months). The number of PDT ranged between 1 and 3 sessions (mean 1.7 sessions). Comparison of the last BCVA of eyes receiving one PDT and eyes being treated by more than one PDT showed a decrease of the mean BCVA by 1 ETDRS line in the first group and an improvement by 2 lines in the second group.

Recurrence of the CNV was seen in one of the 12 eyes after FMT. The recurrent CNV was extrafoveal and treated by laser photocoagulation and intravitreal triamcinolone injection. Chronic macular oedema developed in four of the 12 eyes. No retinal detachment was seen. No patient complained about disturbing diplopia.

One eye developed vitreous haemorrhage and ocular hypotonia after silicone oil removal. Following a repeat of silicone oil installation, the eye stabilised, and intraocular pressure was normal after silicone oil removal.

\section{Discussion}

In this study, the majority of the eyes of the PDT-nonresponders with neovascular AMD had experienced a stabilisation or improvement of visual

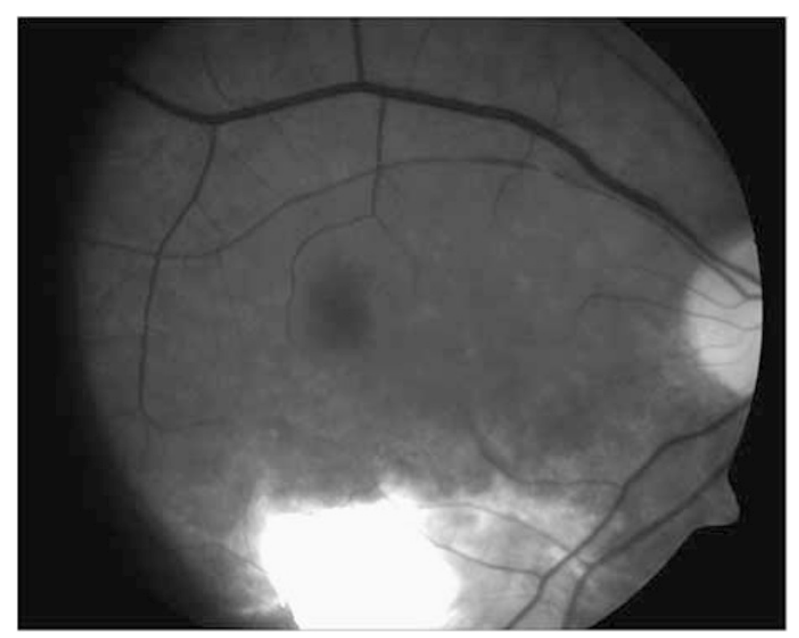

Figure 3 Red-free fundus photograph 18 months after FMT shows a dry macula and surgical coloboma under the macula (visual acuity 20/125).

acuity in a mean follow-up period of 2 years who underwent FMT.

Park and Toth ${ }^{5}$ analysed a group of eight eyes in PDT-nonresponders having undergone FMT. Similar to our results, vision was stabilised in most of cases with a mean visual acuity improvement of six letters. They did not see recurrent $\mathrm{CNV}$ in a mean follow-up period of 10 months. In half of the eyes cystoid macular oedema was detected, similar to our observation. One eye developed a retinal detachment. ${ }^{5}$

Mirshahi $e t a l^{6}$ reported of a case of FMT following PDT. In a follow-up period of 9 months, visual acuity 
increased from $20 / 200$ to $20 / 50$. They noticed an increased adhesion between the CNV and the retina during the FMT. ${ }^{6}$

In our study, one eye experienced recurrence of $\mathrm{CNV}$ 13 months after FMT unlike the study of Park and Toth. ${ }^{5}$ This may be on the basis of the short follow-up period of about 10 months in the latter.

Recurrent CNV after FMT was observed in 3-8\% of eyes. ${ }^{7-9}$ Complication related to FMT included retinal detachment, macular oedema, persistent hypotony, and disturbing diplopia. ${ }^{7-9}$

Our results showed a slightly more favourable visual outcome for patients receiving more than one PDT session before the FMT, differing from the results of Park and Toth. ${ }^{5}$ However, the small sample size analysed in both studies makes a reasonable statement difficult.

The reported increased adhesion of the CNV to the overlying retina after PDT was not noted in our study. Adhesions in the macular area may be possible because of subretinal fibrosis or chorioretinal connections in RAP rather than an effect of PDT.

There are several limitations of our case series. Besides the retrospective character and small number of cases, possible selection bias for the surgery should be mentioned.

FMT is a therapeutic option in patients who are PDT-nonresponders with a long-term lasting effect on stabilisation or improving the visual acuity. However, surgery-related complications must be kept in mind and need to be discussed with the candidates.

\section{References}

1 Ambati J, Ambati BK, Yoo SH, Ianchulex S, Adamis SP. Age-related macular degeneration: etiology, pathogenesis, and therapeutic strategies. Surv Ophthalmol 2003; 48: 257-293.

2 Treatment of Age-related Macular Degeneration With Photodynamic Therapy (TAP) Study Group. Photodynamic therapy of subfoveal choroidal neovascularization in age-related macular degeneration with verteporfin: one-year results of 2 randomized clinical trials-TAP report. Arch ophthalmol 1999; 117: 1329-1345.

3 Machemer R, Steinhorst UH. Retinal separation, retinotomy, and macular relocation: I. Experimental studies in the rabbit eye. Graefe's Arch Clin Exp Ophthalmol 1993; 231: 629-634.

4 Machemer R, Steinhorst UH. Retinal separation, retinotomy, and macular relocation: II. A surgical approach for age-related macular degeneration? Graefe's Arch Clin Exp Ophthalmol 1993; 231: 635-641.

5 Park $\mathrm{CH}$, Toth CA. Macular translocation surgery with 360-degree peripheral retinectomy following ocular photodynamic therapy of choroidal neovascularization. Am J Ophthalmol 2003; 136: 830-835.

6 Mirshahi A, Schreyger F, Baatz H, Scharioth GB. MakulaTranslokation nach photodynamischer Therapie: ein Fallbericht. Klin Monatsbl Augenheilk 2005; 222: 586-589.

7 Aisenbrey S, Lafaut BA, Szurman P, Grisanti S, Lüke C, Krott $\mathrm{R}$ et al. Macular translocation with $360^{\circ}$ retinotomy for exudative age-related macular degeneration. Arch Ophthalmol 2002; 120: 451-459.

8 Abdel-Meguid A, Lappas A, Hartmann K, Auer F, Schrage N, Thumann $\mathrm{G}$ et al. One year follow up of macular translocation with 360 degree retinotomy in patients with age related macular degeneration. Br J Ophthalmol 2003; 87: 615-621.

9 Wong D, Stanga P, Briggs M, Lenfestey P, Lancaster E, Li KK et al. Case selection in macular relocation surgery for age related macular degeneration. Br J Ophthalmol 2004; 88: 186-190. 